\title{
Prevention of distal extension cantilever fracture in
}

\author{
mandibular overdentures.
}

\section{DOI: http://dx.doi.org/10.1016/j.jdent.2015.06.007}

\begin{abstract}
Objectives: Fractures of distal bar extensions, supporting a mandibular overdenture, do occur with significant functional and economic consequences for the patient. This study therefore aims to evaluate the effect of different bar cross-sectional shapes and surfaces, bar extension lengths and the placement of a support rib under the distal bar extension on fracture resistance.

Materials and methods: The $2^{\text {nd }}$ moment area and static strength were calculated for 11 frequently used bar designs using finite element analysis (FEA). For two specific designs (Ackermann round $\varnothing 1.8 \mathrm{~mm}$ and Dolder Y-macro, the former with and without a support rib) additional physical static and fatigue strength tests were included.

Results: The FEA static strength data corresponded well to the $2^{\text {nd }}$ moment area (a similar ranking when maximum allowed force was considered). The application of a rib support (Ackermann $\varnothing 1.8 \mathrm{~mm}$ ) and limitations of the bar extension length ( $6 \mathrm{~mm}$ for the Ackermann $\varnothing 1.8 \mathrm{~mm}, 8 \mathrm{~mm}$ for the Dolder Y-macro) allowed the bars to exceed $5 \times 10^{6}$ cycles of 120 and $250 \mathrm{~N}$ respectively, before fracture. The region of highest stresses in FEA corresponded well with the locations of the fractures observed in static- and fatigue testing. Conclusions: With some simple guidelines/modifications, the number of bar extension fractures can be reduced significantly.
\end{abstract}

\section{Clinical significance}

This study focusses on distal bar extensions which improve the positioning of an implant supported overdenture. By combining laboratory testing and finite element simulations we aim to: (1) explain why fractures occur (dependent on physical characteristics of the bar), and (2) give clinical guidelines on how to prevent such fractures. 


\section{Introduction.}

Although the prevalence of tooth loss has decreased significantly, full edentulism remains a substantial problem in a large part of the population, especially among elderly individuals as edentulism often is postponed to later in life. ${ }^{1,2}$ Conventional full dentures can have a number of flaws including: reduced psychosocial well-being, impaired masticatory function leading to poor nutrition, difficulties in speaking, continuing resorption of the alveolar ridge, and technical complications. ${ }^{3-8}$

A number of randomized-controlled trials reported significantly increased patient satisfaction and a positive impact on quality of life with implant-retained mandibular overdentures compared to conventional dentures. ${ }^{9-11}$ Others reported improvements in chewing ability ${ }^{12}$, as well as in nutritional aspects. ${ }^{13}$ These improvements were found to be stable over time. ${ }^{14}$

Randomized, within-subject, crossover trials on mandibular two-implant-supported prostheses indicated similar patient satisfaction with either a mandibular long-bar implant overdenture or even a fixed fulldental prosthesis. ${ }^{15,16}$ Therefore, a two-implant supported overdenture is considered 'the standard of care' for edentulous lower jaws ${ }^{5,17}$, except for individuals who consider a removable denture as a foreign body. ${ }^{15}$

Although initial reports suggested increased failure rates for implants supporting an overdenture, compared to partial/full fixed bridges (for review see Berglundh et al. $2002^{18}$ ), more recent clinical trials clearly proved the opposite. The cumulative survival rate for implants supporting a mandibular overdenture remains above $96 \%$ after 10 years, with minimal marginal bone loss. ${ }^{19-22}$

A variety of attachment systems is available for mandibular overdentures: ball attachments, bar attachments, or other attachment systems (e.g. magnets). Although there is no hard evidence to prefer one attachment system above the others ${ }^{23}$, all attachments systems have their relative advantages and disadvantages. Magnets, for example, are known to relatively quickly lose their retention capacity ${ }^{24}$ and ball attachments require considerable aftercare. Since a lack of implant parallelism is no restriction for the use of bar attachments, it is a frequently used attachment system. ${ }^{24-26}$ Although infrequent, mechanical failures with bar-supported overdentures have been reported. Besides the prosthesis itself, loosening of the anchoring clips and fractures of the bar and especially the extension cantilevers do occur. ${ }^{23,27}$

To prevent hinging of the overdenture around the bar, distal bar extensions are often added for improved prosthesis stability. ${ }^{28}$ These cantilever bar extensions, however, function as distal lever arms thereby creating higher bending moments on the implants and higher stresses and strains on the supporting implants. $^{29}$

Fracture resistance of distal bar extensions is subject to various bar characteristics. This study aims to evaluate the effect of different bar cross-sectional shapes and surfaces, bar extension length and the placement of a support rib under the distal bar extension on fracture load. A combination of numerical (area, second moment of area, finite element testing (FEA)) and laboratory tests (static and fatigue strength test) were used to evaluate to what extent the bar attachment cross-sectional surface and the placement of a support rib under the distal bar extension affect its fracture risk. The $2^{\text {nd }}$ moment of area was included since it is an important mechanical parameter that defines the deflection, strain, and stress of a bar extension. A lower $2^{\text {nd }}$ moment of area will imply an increased fracture risk. 
Our hypothesis is that the cross-sectional bar design and the corresponding $2^{\text {nd }}$ moment of area play an important role in fracture risk and mechanical behaviour of the structure. We assumed that (1) longer bar extensions negatively influence structure strength, and (2) that the addition of a support rib increases fracture resistance. 


\section{Materials \& methods.}

For this study a number of frequently used bar designs were compared to each other (Table 1). All were subjected to FEA strength analyses, and some designs (representing the micro- and macro- group) were further tested for physical fracture resistance. For the latter the influence of a rib support was also included in this study.

\section{Cross-sections and second moment of area.}

The cross-sections (image and area) of the 11 selected bar designs are shown in Table 1. The area was measured using CAD Software (SpaceClaim Engineer 2012+ by SpaceClaim Corporation 150 Baker Ave. Ext.Concord, MA 1742 USA). Bars with a cross-section area below or above $5 \mathrm{~mm}^{2}$ are referred to as the micro- and macro-bar group, respectively.

Their corresponding $2^{\text {nd }}$ moment of area (area moment of inertia; $I_{x x}$ ) was calculated using the formula: $I_{x x}=\iint_{A}$ $y^{2} d x d y$, with ' $d x d y$ ' being the differential area of the cross-section of the desired shape, and $y$ the distance of the $x$-axis (going through the centre of gravity of the cross-section), to the aforementioned differential area. This differential area is integrated over the entire cross-section area (Table 1).

\section{Finite element analysis (FEA).}

For all bar designs, with distal cantilever extensions of variable length (1 $\mathrm{mm}$ to $10 \mathrm{~mm}$ ), a 3-dimensional computer aided design (CAD) file was created representing an average clinical case (two implants, $21 \mathrm{~mm}$ distance between centres) and identical to the physical test samples. These CAD models were optimized with ANSYS 14.1 (ANSYS, Inc. Pennsylvania, United States) to result in a model that can be used in FEA. A material E-modulus of $110 \mathrm{GPa}$ (Titanium Grade 4, defined with plastic behaviour) with a Poisson ratio of v $=0,37$ was used during FEA simulations. The apical part of the implant cylinders was set as being immobile.

Convergence analysis on element size indicated that a model consisting of 261.347 quadratic tetrahedral elements (C3D10) reached an optimum between mesh size (calculation time) and FEA-result accuracy, compared to physical strength testing. This resulted in a smooth mesh with element size $0.3 \mathrm{~mm}$ to ensure a deformation analogous to the physical structure.

For all 11 bar designs (Table 1), a gradually increasing load was applied on the bar extension at a distance from the cylinder varying from 0.5 to $10 \mathrm{~mm}$ ( $0.5 \mathrm{~mm}$ increments). When the ultimate stress, indicating fracture, was reached, the applied force was recorded as maximum allowed force.

For three selected structures (Ackermann round $\varnothing 1.8 \mathrm{~mm}$ bar without and with rib support, both loaded at $6 \mathrm{~mm}$ away from the cylinder/extension junction, and Dolder Y-macro bar loaded at $8 \mathrm{~mm}$, respectively), physical static loading was simulated. Loading was applied in a unilateral vertical direction ( $0 \mathrm{~N}$ preload, $150 \mathrm{~N}$ load), similar to the loading used in the physical static and fatigue strength test below. This loading protocol corresponds to a worst case loading in vivo. 


\section{Physical static and fatigue strength test.}

The Ackermann round $\varnothing 1.8 \mathrm{~mm}$ bar and the Dolder Y-macro profile were selected for the physical static and fatigue strength tests because they are worst case designs (weakest representatives) from the micro- and macro subgroup respectively according to their second moment of area and coupled deflection. In addition, the effect of a rib support for the Ackermann round $\varnothing 1.8 \mathrm{~mm}$ bar was evaluated.

From each of these three designs, 17 physical samples (bar, 2 cylinders, 1 distal cantilever extension) were milled (through CAM, computer-assisted manufacturing) in Titanium Grade 4 (Dentsply Implants NV., Atlantis ISUS, Hasselt, Belgium). The bars with cylinders were screwed on special fixtures (fulfilling the requirements reported in ISO 14801:2007 (Fig. 1)), analogous to the clinical fixation, and fixed in solid acrylic holders. The inter-implant distance (centre-centre) was $21 \mathrm{~mm}$, representing an average clinical condition.

For the static strength test, five samples of each structure were placed in a dynamic table-top testing machine (AeroCIMTronic 2000, DynaMess, Germany). Strict vertical forces were applied (via a knife shaped piston) on the extension in a provision groove at the specific distance from the cylinder (6 $\mathrm{mm}$ for the Ackerman bar, $8 \mathrm{~mm}$ for the Dolder-Y macro bar extensions), to prevent slipping of the piston during the test and to ensure that the loading is consistent and stable. The loading regime consisted of a preload of $0 \mathrm{~N}$ followed by a progressive compression of $0.01 \mathrm{~mm} / \mathrm{s}$ until fracture occurred. This loading method corresponds to an excessive worst case loading in vivo. Failure was defined as a sudden $20 \%$ decrease in recorded force, due to fracture of the bar extension. For each of the samples the static for to fracture was recorded.

In a second series of tests, the threshold load needed to fracture the distal cantilever extension under repetitive loading (fatigue strength test) was investigated. Fatigue testing was carried out with an unidirectional vertical load that varied sinusoïdally between a nominal peak value and $10 \%$ of this value, at a loading frequency of $15 \mathrm{~Hz}$ (dynamic table-top testing machine, AeroCIMTronic 2000, DynaMess, Germany) using the same fixture as the static strength test (Fig. 1). The test was repeated (each time involving three new bars) with 10\% lower maximal load until a lower limit (maximum endured load) was reached at which all three specimens survived $5 \times 10^{6}$ cycles. The dynamic tests were performed at room temperature.

\section{Statistics.}

The data of the static strength test was compared between the three selected bar designs (Ackermann with vs. without rib support, and Ackermann with rib support vs. Dolder-Y bar) via a Mann-Whitney $U$ test applying a Bonferroni correction for repeated analyses. 
Results.

\section{Cross-sections and second moment of area.}

The area of the cross-sections from the different bars ranged from 2.5 to $4.1 \mathrm{~mm}^{2}$ for the so called microdesigns and from 5.4 to $7.9 \mathrm{~mm}^{2}$ for the macro-designs. The $2^{\text {nd }}$ moment of area ranged from 0.52 to 7.11 $\mathrm{mm}^{4}$ (0.6 $-2.3 \mathrm{~mm}^{4}$ for the micro- and $3.2-7.1 \mathrm{~mm}^{4}$ for the macro-designs, respectively) (Table 1). For rounded bars a larger cross-section area leads to a larger second moment of area, which is not necessarily the case for not rounded bars.

\section{Finite element analysis (FEA).}

The calculated fracture load for the 11 bar designs, with a loading at different distances to the cylinder, is shown in figure 2 . The resistance to fracture was perfectly in line with the ranking of the $2^{\text {nd }}$ moment of area (Table 1). Both the Ackermann bar and the Dolder-Y bar performed worst in the micro- and macro-group, respectively. A larger extension length clearly negatively influenced the maximal allowed force (Fig. 2). Within, as well as between the micro- and macro profiles a similar relationship between loading distance and fracture load was observed.

The 3 FEA images at maximal load (150N, Fig. 3) illustrate the stress concentration at different locations within the bar extensions:

- for the Ackermann bar without rib high stress values close to the cylinder,

- for the same bar but with rib support a reduced stress more equally distributed over the extension,

- $\quad$ and for the Dolder-Y bar clearly lower stresses, 25\% lower when loaded under similar conditions. The stress pattern is similar for both bars without supporting rib.

\section{Physical static and fatigue strength test.}

The results of the static load to failure (Table 3) gave a first comparison between the 3 tested bar designs. The addition of a support rib to the Ackermann bar increased significantly $(p<0.01)$ the static force at fracture by $48 \%(150 \mathrm{~N}$ to $222 \mathrm{~N})$. The Dolder-Y macro bar ( $421 \mathrm{~N}$ static load at failure) was almost twice as strong as the Ackermann micro bar (with rib, $p<0.01$ ).

The Wöhler curve (Fig. 4) displayed the behaviour of the tested bar designs when loaded cyclically (to mimic fatigue). For each measurement, the load and amount of cycles until fracture occurred are indicated. The Ackerman bar without rib support showed a relative low resistance to fatigue fracture (force at failure after $5 \times 10^{6}$ cycles: $80 \mathrm{~N}$, Table 2). The addition of a rib support at the cylinder/extension junction led to a $58 \%$ increase $(126 \mathrm{~N})$ of the fatigue strength. The Dolder-Y macro bar resisted clearly higher fatigue forces (240 N for even an $8 \mathrm{~mm}$ extension). Both parameters correlated well with each other, and with the previous FEA results (Fig. 2\&3).

The fracture analyses indicated a recurrent 3-D position of the fracture as well as a good correlation between FEA analysis (Fig. 3) and the fracture location during fatigue strength test (Fig. 5). Both Ackermann and Dolder-Y bars fractured immediately distally to the cylinder. For the Ackermann bar with support rib, fracture occurred distally to the support rib. 


\section{Discussion}

Distal bar extension fracture is a known clinical complication in overdenture patients. ${ }^{30-36}$ This study aimed at gaining insight in the effect of bar design ${ }^{37}$ on its fatigue strength. The hypothesis was that the following distal bar extension features (bar cross-sectional area, bar design, bar extension length, and a rib support) had a significant impact on their resistance to fracture.

The bar cross-section area was used to calculate the $2^{\text {nd }}$ moment of area. For a given design, an increase in cross-section area resulted in a larger $2^{\text {nd }}$ moment of area, and thus in a smaller deflection (bending) at loading, and consequently a reduced chance to fracture. As such the Ackermann bar ( $\varnothing 1.8 \mathrm{~mm})$ should be considered as less resistant to fracture when compared to the Bredent round ( $\varnothing 2.0 \mathrm{~mm})$. Besides the cross-sectional area, also the design as such affected the $2^{\text {nd }}$ moment of area, explaining why for example the Dolder Y-micro and Bredent VSP-FS bar revealed a higher $2^{\text {nd }}$ moment of area compared to the Bredent round $\varnothing 2.0 \mathrm{~mm}$ and Dolder U-macro bar respectively, despite smaller cross-sectional areas. This is due to the fact that the shape of the cross-section plays an important role in the calculation of the second moment of area. High, narrow shapes result in a higher second moment of area than short wide shapes. The same is seen when comparing Dolder U macro and Bredent VSP-FS.

Finite element analysis was used to provide quantitative information on the load at which different bar designs fracture (Fig. 2). The observed resistance to fracture was perfectly in line with the ranking of the $2^{\text {nd }}$ moment of area for the different bars (Table 1). For the micro-group, the Ackermann bar was found to be the weakest, and the Bredent wbgs $<$ the strongest. For the macro-group, the Dolder-Y performed the worst, and the Bredent wbgs> the best. The analyses also indicated that a more posterior application of the load (thus further away from the cylinder, representing a longer bar) resulted in lower resistance to fracture. Thus, bar extensions should not be too long. ${ }^{28,36,37}$ This is also obvious from a mechanical point of view, since the load application (bar length) acts as a cantilever (Katsoulis et al $2013^{30}$, Waddell et al $2006^{34}$, Rasmussen et al $\left.2006^{35}\right)$ and influences the fracture load to the third power $\left(F=\left(3^{\star} E^{\star} \mid{ }^{\star} \delta\right) /\left(L^{3}\right)\right)$. This formula also explains the shape of the curves in figure 2. However, due to shortcomings of FE research (analysis with unidirectional loading, material properties, using an 'idealized' CAD model, ...) the results of figure 2 may not "mathematically" be extrapolated to the clinic. Figure 2 has its use only in: (1) comparing different bar profiles, and (2) indicating the effect of bar length.

FEA was also used to analyse the stress distribution in some supra-structures (Fig. 3). FEA indicated a clear stress concentration at the cylinder/extension junction in the non-rib supported Ackermann bar and Dolder-Y bar, however with lower concentrations for the latter. The rib support resulted in a reduction and a more equal distribution of the stresses in the extension bar. Moreover, the highest stress values were now located distally of the rib support. As such, bending mainly happens in the distal part of the bar extension, behind the supporting rib.

The static and fatigue tests (Table 2, Fig. 4) indicated that the resistance to fracture was relatively low for an Ackermann $\varnothing 1.8 \mathrm{~mm}$ round bar $(80 \mathrm{~N})$. The application of a rib support increased the resistance to fracture significantly $(126 \mathrm{~N})$, suggesting that this could be an efficient preventive intervention. From a clinical perspective, however, one should keep in mind that such rib support requires certain dimension, which in turn 
requires sufficient inter-occlusal space in order to allow optimal oral hygiene ${ }^{38}$. With the Dolder-Y macro bar, the fatigue force was clearly higher, even for a longer extension ( $8 \mathrm{~mm}$ and $240 \mathrm{~N}$ ).

The analysis of the fractured bars, after fatigue testing, showed a perfect match between the 3-D location of the fracture on one hand, and the stress concentrations observed in FEA on the other hand (Fig. 5), with fractures immediately behind the cylinder (Ackermann and Dolder-Y bar) or the rib support. This corresponded also very well with the experience of the Atlantis ISUS milling centre (Dentsply Implants NV. Hasselt). When analysing their mechanical complications with the milled Ackermann bars, $90 \%$ of the fractures were located at the same position. Literature confirms that bar extension fractures were located in this part of the bar extension. ${ }^{30}$

The above mentioned forces (resistance to fracture, e.g. $80 \mathrm{~N}$ for Ackermann) have to be considered in a clinical perspective. Meriscke-Stern ${ }^{39}$ examined the amount of force transmitted to two implants supporting an overdenture with two distal bar extensions. The maximum force applied to the implants with the dentures in centric occlusion reached $96.2 \mathrm{~N}( \pm 62.2 \mathrm{~N})$ in a vertical direction. These values increased to $149.3 \mathrm{~N}( \pm 62.1 \mathrm{~N})$ at the ipsi-lateral implant when a bite plate was placed at the $2^{\text {nd }}$ premolar. In the bite plate itself a force of $171.6 \mathrm{~N}( \pm 47.9 \mathrm{~N})$ was recorded. These observations suggest that, under special conditions, a similar force can reach the extension bar (e.g. non-optimal fit between denture and bar, or hinging of denture after further resorption of the alveolar crest).

Occlusal loads on an overdenture normally will also be transferred to the mucosa. In case of overdentures supported by bar (without distal cantilevers) or ball attachments, a distribution of the load between implants and mucosa is observed. When a bar with distal extensions is used however, less loads are transferred to the underlying mucosa because the distal extensions prevent a hinging of the overdenture around the bar during function. ${ }^{29}$ The small difference between force values in bite plate and the ipsi lateral implant, observed by Meriscke-Stern ${ }^{39}$, confirms the minimal force absorption capacity of the denture and/or mucosa itself for an overdenture with extension bars.

Our observations should, however, be put into perspective. It has never been the intention to predict clinical force values, but only to relatively compare bar designs, to verify the effect of a rib support, and to validate the importance of the length of the extension bar. Indeed a number of methodological shortcomings could jeopardise the direct extrapolation from our registered forces to clinical practise. These shortcomings include:

- $\quad$ the use of a point load (knife shaped piston) instead of a more distributed load (via retainers), ${ }^{39}$

- the absence of a denture and mucosa (even though their influence seems negligible),

- the absence of an abutment-implant junction (in this study the bar, extension bar, the abutments and implants formed one milled entity),

- the fixation of this entity via an acrylic sleeve in metal holders (instead of alveolar bone, also strains in this region are not significantly influenced by bar cantilever length ${ }^{39-41}$ ). However, the static and fatigue tests matched well with our predicted parameters $\left(2^{\text {nd }}\right.$ moment of area, FE analyses), which can support our methodology. The latter is further confirmed by the experience of the Atlantis ISUS milling centre (Dentsply Implants NV., Hasselt). When evaluating retrospectively all bar extension fractures, the frequency was 3 times higher for the Ackermann $\varnothing 1.8 \mathrm{~mm}$, than for example the 
Dolder-Y macro profile. However, after the introduction of the rib support, the percentage of fractures dropped by $70 \%$.

\section{Conclusion.}

Within the limitations of numerical and laboratory tests, this study indicated that the bar cross-section area, the bar design, the second moment of area, and the length of the bar extension all affect its fatigue strength. The lowest strengths were observed for the three micro round bars (Ackermann, Bredent). This can be partially compensated by adding a support rib. The threshold length of a bar extension, without major risks for fracture, is bar design dependent (e.g. a Dolder-Y bar can go to $8 \mathrm{~mm}$ for a cyclic load of $\pm 200 \mathrm{~N}$ ). 


\section{REFERENCES.}

[1] Müller F, Naharro M, Carlsson GE. What are the prevalence and incidence of tooth loss in the adult and elderly population in Europe? Clinical Oral Implants Research 2007;18 Suppl 3:2-14. doi:10.1111/j.1600-0501.2007.01459.x.

[2] Polzer I, Schimmel M, Müller F, Biffar R. Edentulism as part of the general health problems of elderly adults. International Dental Journal 2010;60:143-55.

[3] Allen PF, McMillan AS. The impact of tooth loss in a denture wearing population: an assessment using the Oral Health Impact Profile. Community Dental Health 1999;16:176-80.

[4] Sheiham A, Steele JG, Marcenes W, Lowe C, Finch S, Bates CJ, et al. The relationship among dental status, nutrient intake, and nutritional status in older people. Journal of Dental Research 2001;80:40813.

[5] Feine JS, Carlsson GE, Awad MA, Chehade A, Duncan WJ, Gizani S, et al. The McGill Consensus Statement on Overdentures. Montreal, Quebec, Canada. May 24-25, 2002. The International Journal of Prosthodontics 2002;15:413-4.

[6] Ellis JS, Thomason JM, Jepson NJ, Nohl F, Smith DG, Allen PF. A randomized-controlled trial of food choices made by edentulous adults. Clinical Oral Implants Research 2008;19:356-61.

doi:10.1111/j.1600-0501.2007.01488.x.

[7] Heydecke G, Thomason JM, Awad MA, Lund JP, Feine JS. Do mandibular implant overdentures and conventional complete dentures meet the expectations of edentulous patients? Quintessence International (Berlin, Germany: 1985) 2008;39:803-9.

[8] Hyland R, Ellis J, Thomason M, El-Feky A, Moynihan P. A qualitative study on patient perspectives of how conventional and implant-supported dentures affect eating. Journal of Dentistry 2009;37:718-23. doi:10.1016/j.jdent.2009.05.028.

[9] Boerrigter EM, Geertman ME, Van Oort RP, Bouma J, Raghoebar GM, van Waas MA, et al. Patient satisfaction with implant-retained mandibular overdentures. A comparison with new complete dentures not retained by implants--a multicentre randomized clinical trial. The British Journal of Oral \& Maxillofacial Surgery 1995;33:282-8.

[10] Thomason JM. The use of mandibular implant-retained overdentures improve patient satisfaction and quality of life. The Journal of Evidence-Based Dental Practice 2010;10:61-3. doi:10.1016/j.jebdp.2009.11.022.

[11] Awad MA, Rashid F, Feine JS. The effect of mandibular 2-implant overdentures on oral health-related quality of life: an international multicentre study. Clinical Oral Implants Research 2014;25:46-51. doi:10.1111/clr.12205.

[12] Meijer HJA, Raghoebar GM, Van 't Hof MA. Comparison of implant-retained mandibular overdentures and conventional complete dentures: a 10-year prospective study of clinical aspects and patient satisfaction. The International journal of oral \& maxillofacial implants 2003;18:879-85.

[13] Moynihan PJ, Elfeky A, Ellis JS, Seal CJ, Hyland RM, Thomason JM. Do implant-supported dentures facilitate efficacy of eating more healthily? Journal of Dentistry 2012;40:843-50. doi:10.1016/j.jdent.2012.07.001.

[14] Jabbour Z, Emami E, de Grandmont $\mathrm{P}$, Rompré $\mathrm{PH}$, Feine JS. Is oral health-related quality of life stable following rehabilitation with mandibular two-implant overdentures? Clinical Oral Implants Research 2012;23:1205-9. doi:10.1111/j.1600-0501.2011.02289.x. 
[15] Feine JS, de Grandmont P, Boudrias P, Brien N, LaMarche C, Taché R, et al. Within-subject comparisons of implant-supported mandibular prostheses: choice of prosthesis. Journal of Dental Research 1994;73:1105-11.

[16] Feine JS, Maskawi K, de Grandmont P, Donohue WB, Tanguay R, Lund JP. Within-subject comparisons of implant-supported mandibular prostheses: evaluation of masticatory function. Journal of Dental Research 1994;73:1646-56.

[17] Thomason JM, Kelly SAM, Bendkowski A, Ellis JS. Two implant retained overdentures--a review of the literature supporting the McGill and York consensus statements. Journal of Dentistry 2012;40:22-34. doi:10.1016/j.jdent.2011.08.017.

[18] Berglundh T, Persson L, Klinge B. A systematic review of the incidence of biological and technical complications in implant dentistry reported in prospective longitudinal studies of at least 5 years. Journal of Clinical Periodontology 2002;29 Suppl 3:197-212; discussion 232-3.

[19] Meijer HJA, Raghoebar GM, Batenburg RHK, Vissink A. Mandibular overdentures supported by two Brånemark, IMZ or ITI implants: a ten-year prospective randomized study. Journal of Clinical Periodontology 2009;36:799-806. doi:10.1111/j.1600-051X.2009.01442.x.

[20] Ma S, Tawse-Smith A, Thomson WM, Payne AGT. Marginal bone loss with mandibular two-implant overdentures using different loading protocols and attachment systems: 10-year outcomes. The International Journal of Prosthodontics 2010;23:321-32.

[21] Vercruyssen M, Quirynen M. Long-term, retrospective evaluation (implant and patient-centred outcome) of the two-implant-supported overdenture in the mandible. Part 2: marginal bone loss. Clinical Oral Implants Research 2010;21:466-72. doi:10.1111/j.1600-0501.2009.01902.x.

[22] Stoker G, van Waas R, Wismeijer D. Long-term outcomes of three types of implant-supported mandibular overdentures in smokers. Clinical Oral Implants Research 2012;23:925-9. doi:10.1111/j.1600-0501.2011.02237.x.

[23] Cehreli MC, Karasoy D, Kokat AM, Akca K, Eckert SE. Systematic review of prosthetic maintenance requirements for implant-supported overdentures. The International Journal of Oral \& Maxillofacial Implants 2010;25:163-80.

[24] Naert I, Alsaadi G, Quirynen M. Prosthetic aspects and patient satisfaction with two-implant-retained mandibular overdentures: a 10-year randomized clinical study. The International journal of prosthodontics 2004;17:401-10 doi:10.1016/j.prosdent.2004.09.021.

[25] Naert I, Alsaadi G, van Steenberghe D, Quirynen M. A 10-year randomized clinical trial on the influence of splinted and unsplinted oral implants retaining mandibular overdentures: peri-implant outcome. The International Journal of Oral \& Maxillofacial Implants 2004;19:695-702.

[26] Stoker GT, Wismeijer D, van Waas MAJ. An eight-year follow-up to a randomized clinical trial of aftercare and cost-analysis with three types of mandibular implant-retained overdentures. Journal of Dental Research 2007;86:276-80.

[27] Chen K-W, Lin T-M, Liu P-R, Ramp LC, Lin H-J, Wu C-T, et al. An analysis of the implant-supported overdenture in the edentulous mandible. Journal of Oral Rehabilitation 2013;40:43-50.

doi:10.1111/joor.12010.

[28] Mericske-Stern RD, Taylor TD, Belser U. Management of the edentulous patient. Clinical Oral Implants Research 2000;11 Suppl 1:108-25.

[29] Duyck J, Van Oosterwyck H, Vander Sloten J, De Cooman M, Puers R, Naert I. In vivo forces on oral implants supporting a mandibular overdenture: the influence of attachment system. Clinical Oral Investigations 1999;3:201-7. 
[30] Katsoulis J, Wälchli J, Kobel S, Gholami H, Mericske-Stern R. Complications with Computer-Aided Designed/Computer-Assisted Manufactured Titanium and Soldered Gold Bars for Mandibular ImplantOverdentures: Short-Term Observations. Clinical Implant Dentistry and Related Research 2013;17 Suppl 1:e75-85. doi:10.1111/cid.12130.

[31] Dudic A, Mericske-Stern R. Retention mechanisms and prosthetic complications of implant-supported mandibular overdentures: Iong-term results. Clinical Implant Dentistry and Related Research 2002;4:212-9.

[32] Elsyad MA, Al-Mahdy YF, Salloum MG, Elsaih EA. The effect of cantilevered bar length on strain around two implants supporting a mandibular overdenture. The International Journal of Oral \& Maxillofacial Implants 2013;28:e143-50.

[33] Kuoppala R, Näpänkangas R, Raustia A. Outcome of implant-supported overdenture treatment - A survey of 58 patients. Gerodontology 2012;29:e577-84. doi:10.1111/j.1741-2358.2011.00524.x.

[34] Waddell JN, Payne AGT, Swain M V. Physical and metallurgical considerations of failures of soldered bars in bar attachment systems for implant overdentures: A review of the literature. The Journal of Prosthetic Dentistry 2006;96:283-8. doi:10.1016/j.prosdent.2006.07.005.

[35] Rasmussen JM, Koka S, Eckert SE, Lee RD. Repair of a milled cantilevered implant overdenture bar: a clinical report. The Journal of Prosthetic Dentistry 2006;96:84-7. doi:10.1016/j.prosdent.2006.04.008.

[36] Waddell JN, Payne AGT, Swain M V, Kieser JA. Scanning electron microscopy observations of failures of implant overdenture bars: a case series report. Clinical Implant Dentistry and Related Research 2010;12:26-38. doi:10.1111/j.1708-8208.2008.00127.x.

[37] Misch C. Dental implant prosthetics. Elsevier; 2004.

[38] Krennmair G, Krainhöfner M, Piehslinger E. The influence of bar design (round versus milled bar) on prosthodontic maintenance of mandibular overdentures supported by 4 implants: a 5 -year prospective study. The International Journal of Prosthodontics 21:514-20.

[39] Mericske-Stern R. Force distribution on implants supporting overdentures: the effect of distal bar extensions. A 3-D in vivo study. Clinical Oral Implants Research 1997;8:142-51.

[40] Cekiç C, Akça K, Cehreli MC. Effects of attachment design on strains around implants supporting overdentures. Quintessence International (Berlin, Germany : 1985) 2007;38:e291-7.

[41] Semper W, Heberer S, Nelson K. Retrospective analysis of bar-retained dentures with cantilever extension: marginal bone level changes around dental implants over time. The International Journal of Oral \& Maxillofacial Implants 2010;25:385-93. 


\section{Tables}

Table 1. Cross-section image, cross-section area and second moment of area of different bar designs ranked by $2^{\text {nd }}$ moment of area.

\begin{tabular}{|c|c|c|c|}
\hline Type of bar & $\begin{array}{c}\text { Cross section } \\
\text { image }\end{array}$ & $\begin{array}{c}\text { Cross section } \\
\text { area }\left(\mathrm{mm}^{2}\right)\end{array}$ & $\begin{array}{l}2^{\text {nd }} \text { moment of } \\
\text { area }\left(\mathrm{mm}^{4}\right)^{*}\end{array}$ \\
\hline & \multicolumn{3}{|c|}{ "Micro - bars" } \\
\hline Ackermann round $\varnothing 1.8 \mathrm{~mm}^{\$}$ & & 2.5 & 0.52 \\
\hline Bredent round $\emptyset 1.9 \mathrm{~mm}$ & & 2.8 & 0.64 \\
\hline Bredent round $\emptyset 2.0 \mathrm{~mm}$ & & 3.1 & 0.78 \\
\hline Dolder Y-micro & & 3.0 & 1.21 \\
\hline Preci-horix & & 3.2 & 1.31 \\
\hline Dolder U-micro & & 3.4 & 1.37 \\
\hline \multirow[t]{2}{*}{ Bredent wbgs $<$} & & 4.1 & 2.27 \\
\hline & \multicolumn{3}{|c|}{ "Macro - bars" } \\
\hline Dolder Y-macro $\$$ & & 5.4 & 3.20 \\
\hline Dolder U-macro & & 6.1 & 4.07 \\
\hline Bredent VSP-FS & & 5.0 & 5.51 \\
\hline Bredent wbgs > & & 7.9 & 7.11 \\
\hline \multicolumn{4}{|c|}{$\begin{array}{l}\text { \$Bars tested via physical static and fatigue test (Ackermann bar with and without support rib). } \\
\text { * The } 2^{\text {nd }} \text { moment of area is one of the components that defines the deflection, and strain, of an end loaded } \\
\text { cantilever beam (bar extension), according to the formula of the deflection: } \delta=\left(F^{*} L^{3}\right) /\left(3^{\star} E^{\star} l\right) \text { (with } F=\text { force, } L= \\
\text { extension length, } E=E \text {-modulus of the material and I = second moment of area). A lower } 2^{\text {nd }} \text { moment of area, } \\
\text { under the same loading conditions and using the same material, will therefore result in a higher deflection }\end{array}$} \\
\hline
\end{tabular}


Table 2. Physical static (with standard deviation) and fatigue test data for different bar designs (Ackermann round $\varnothing 1.8 \mathrm{~mm}$ without and with rib support, loaded at $6 \mathrm{~mm}$ away from the cylinder/extension junction, and Dolder Y-macro bar, loaded at $8 \mathrm{~mm}$ away from the cylinder/extension junction respectively.

\begin{tabular}{|l|c|c|c|c|}
\hline Type of bar & $\begin{array}{c}\text { extension } \\
\text { length }\end{array}$ & $\begin{array}{c}\text { rib } \\
\text { support }\end{array}$ & $\begin{array}{c}\text { static force to } \\
\text { fracture }\end{array}$ & $\begin{array}{c}\text { 'fatigue' force without } \\
\text { fracture after } 5 \times 10^{6} \\
\text { cycles }\end{array}$ \\
\hline Ackermann round $\varnothing 1.8 \mathrm{~mm}$ & $6 \mathrm{~mm}$ & no & $150+/-4 \mathrm{~N}$ & $80 \mathrm{~N}$ \\
\hline Ackermann round $\varnothing 1.8 \mathrm{~mm}$ & $6 \mathrm{~mm}$ & yes & $222+/-5 \mathrm{~N}$ & $126 \mathrm{~N}$ \\
\hline Dolder Y-macro & $8 \mathrm{~mm}$ & no & $421+/-10 \mathrm{~N}$ & $240 \mathrm{~N}$ \\
\hline
\end{tabular}




\section{FIGURES}

\section{Figure 1.}

Set-up for the physical static and fatigue strength test. The samples were mounted on a special fixture (based on ISO 14801:2007). Each sample consisted of two cylinders, connected by a bar, which were fixed in a solid acrylic holder (under a $30^{\circ}$ angle). The span between both cylinders $(21 \mathrm{~mm})$ represents an average clinical supra-structure. Forces were applied (via a knife shaped piston) at a specific distance from the cylinder; 6 $\mathrm{mm}$ for Ackermann bar, and $8 \mathrm{~mm}$ for Dolder-Y macro bar respectively, in a provision groove (to prevent slipping of the piston during the test).

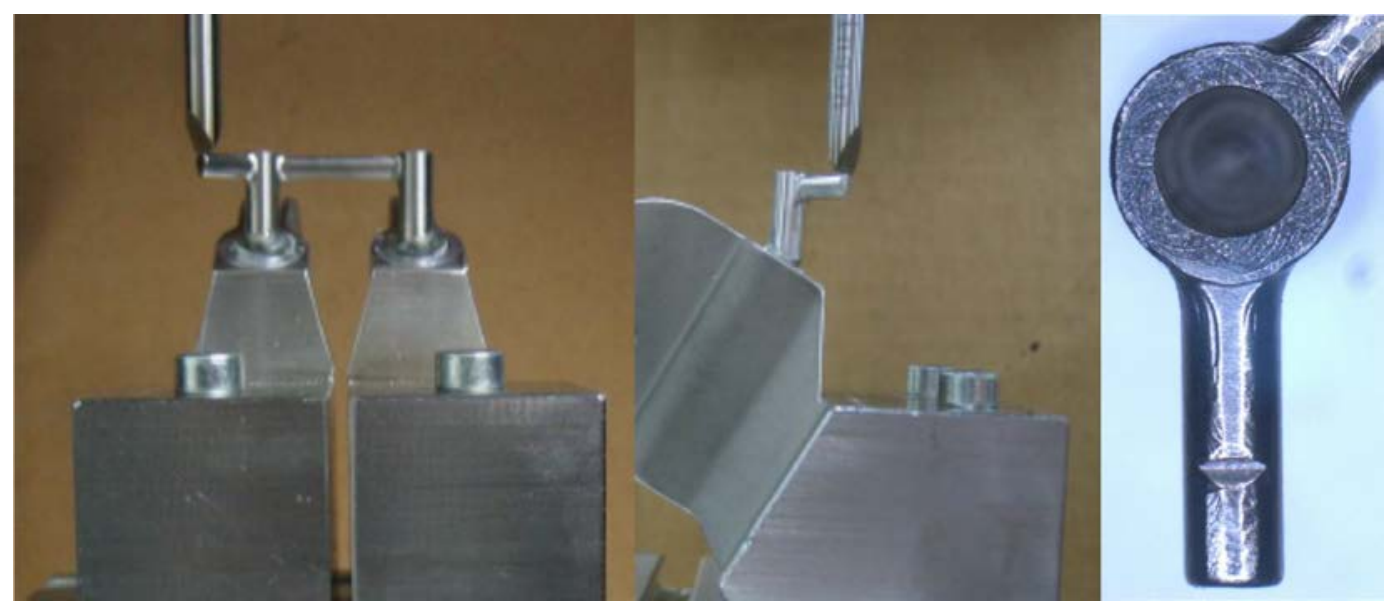


Figure 2.

FEA strength results for all bar designs, representing the fracture load $(\mathrm{N})$ in relation to the loading distance (distance in $\mathrm{mm}$ from the cylinder where the load was applied). Following bar profiles (milled in Titanium Grade 4) are included: Ackermann round $\varnothing 1.8 \mathrm{~mm}$ (Ack Ø1.8), Bredent round $\varnothing 1.9 \mathrm{~mm}$ (Bre $\varnothing 1.9)$, Bredent round $\varnothing 2.0 \mathrm{~mm}$ (Bre Ø2.0), Bredent wbgs < (Brewbgs <), Bredent wbgs > (Brewbgs >), Bredent VSP-FS (Brevspfs), Dolder Y-micro (DolderY <), Dolder Y-macro (DolderY >), Dolder U-micro (DolderU <), Dolder Umacro (DolderU >), Preci-horix (Preci).

Due to a number of shortcomings (FEA analysis, CAD model, material assumptions) these data are only valuable for inter-bar design comparison, but cannot be mathematically extrapolated to the clinic

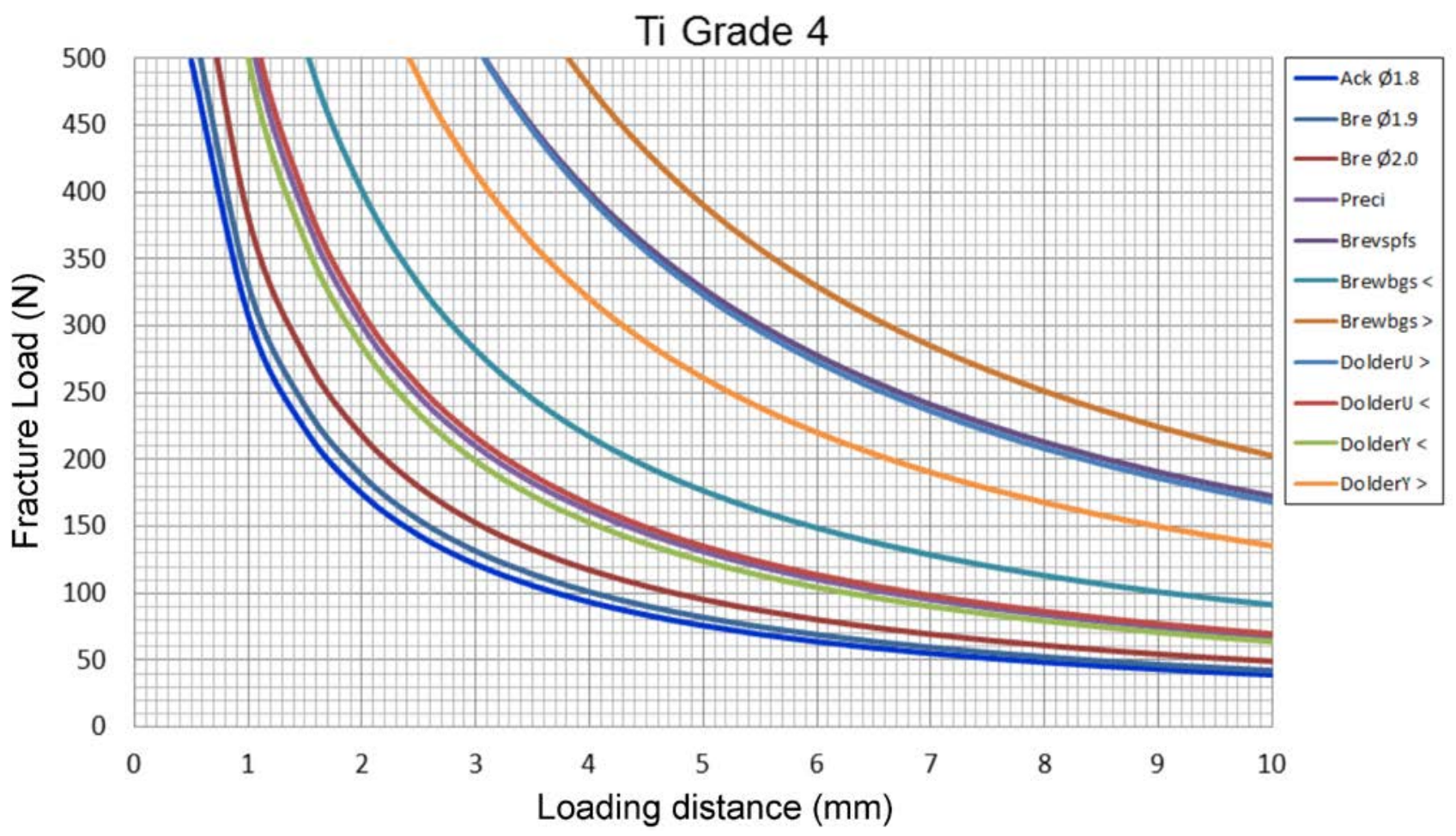


Figure 3.

FEA images (with stress distribution in MPa and resulting deformation) of a $150 \mathrm{~N}$ load application on an (top to bottom) Ackermann round $\varnothing 1.8 \mathrm{~mm}$ bar without and with rib support at $6 \mathrm{~mm}$ away from the cylinder/extension junction, and on a Dolder Y-macro bar loaded at $8 \mathrm{~mm}$ respectively. The colour scale (blue corresponds to no stress, red indicates the location of maximal stress, identical scale for all three structures) indicates the values of the Von Mises stress (a combination of tensile and compressive stresses). These stress distributions can be used to compare selected bar designs, and serve as an indication of fracture location. Both top view (left) and isometric view (right) are shown. The top view of the Ackermann bar without rib support seems smaller due to the excessive bending.
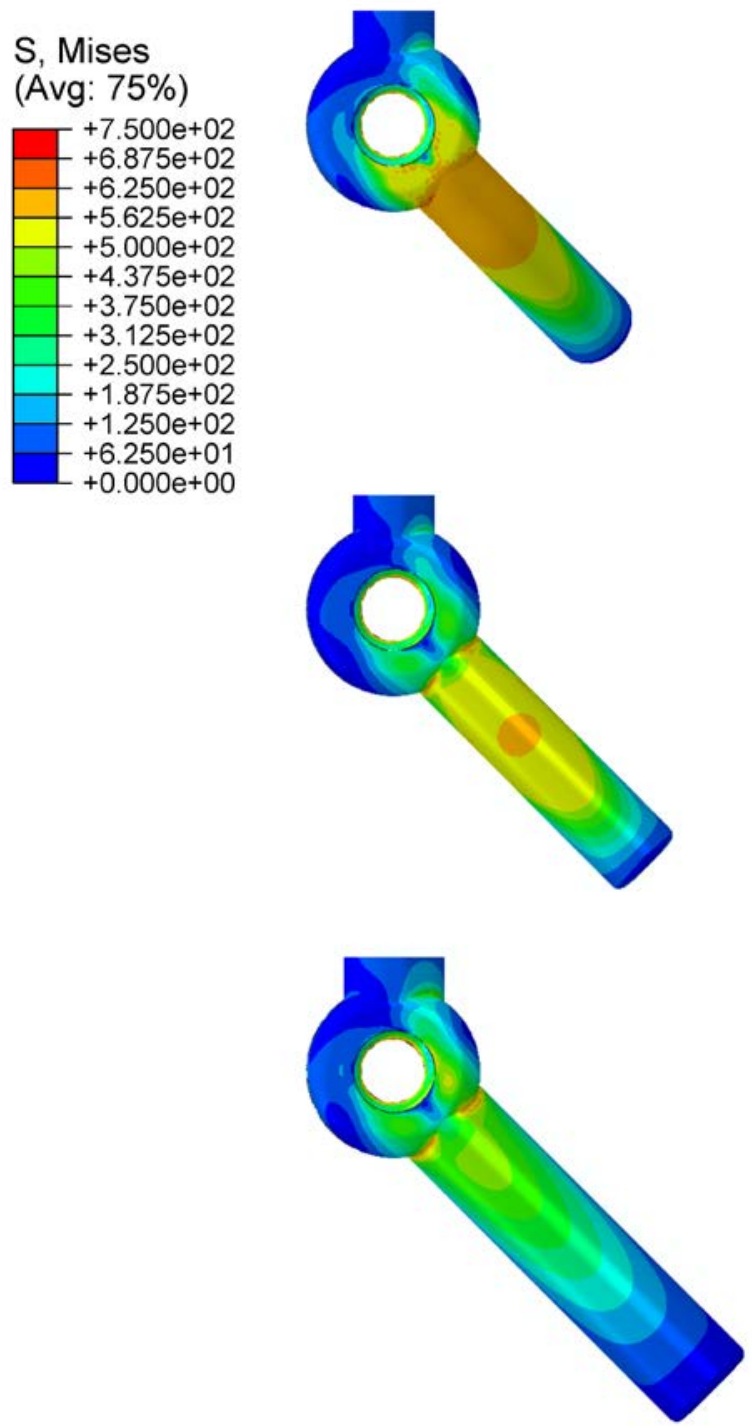
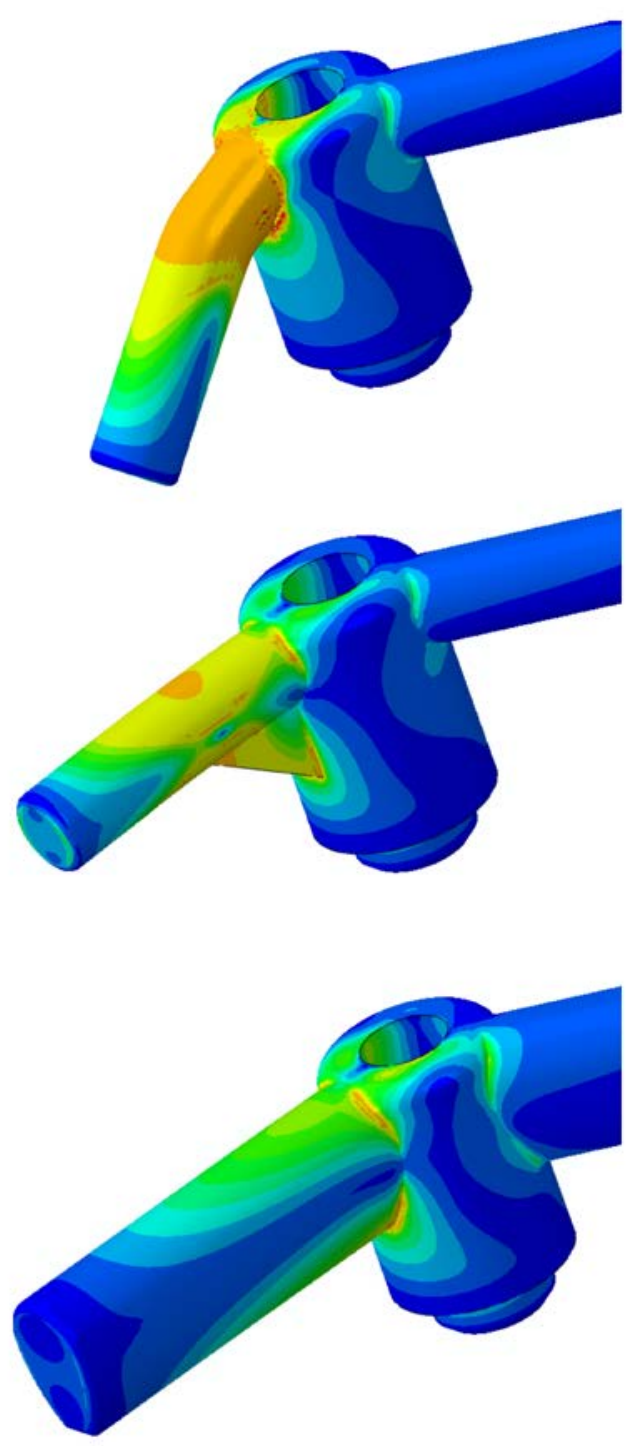
Figure 4.

Magnitude of a cyclic stress (maximum applied load in $\mathrm{N}$ ) against cycles to failure (the latter expressed in a logarithmic scale). The fatigue test was performed on following bar designs: Ackermann round $\varnothing 1.8 \mathrm{~mm}$ bar without (AckØ1.8) and with rib support (AckØ1.8+rib), each time loaded at $6 \mathrm{~mm}$ away from the cylinder/extension junction, and Dolder Y-macro bar at $8 \mathrm{~mm}$ (DolderY> 8), respectively. For each maximum applied load, three bars were analysed. In some cases there is a run-out where the time to failure exceeds $5 \times 10^{6}$ cycles (indicated with '>').

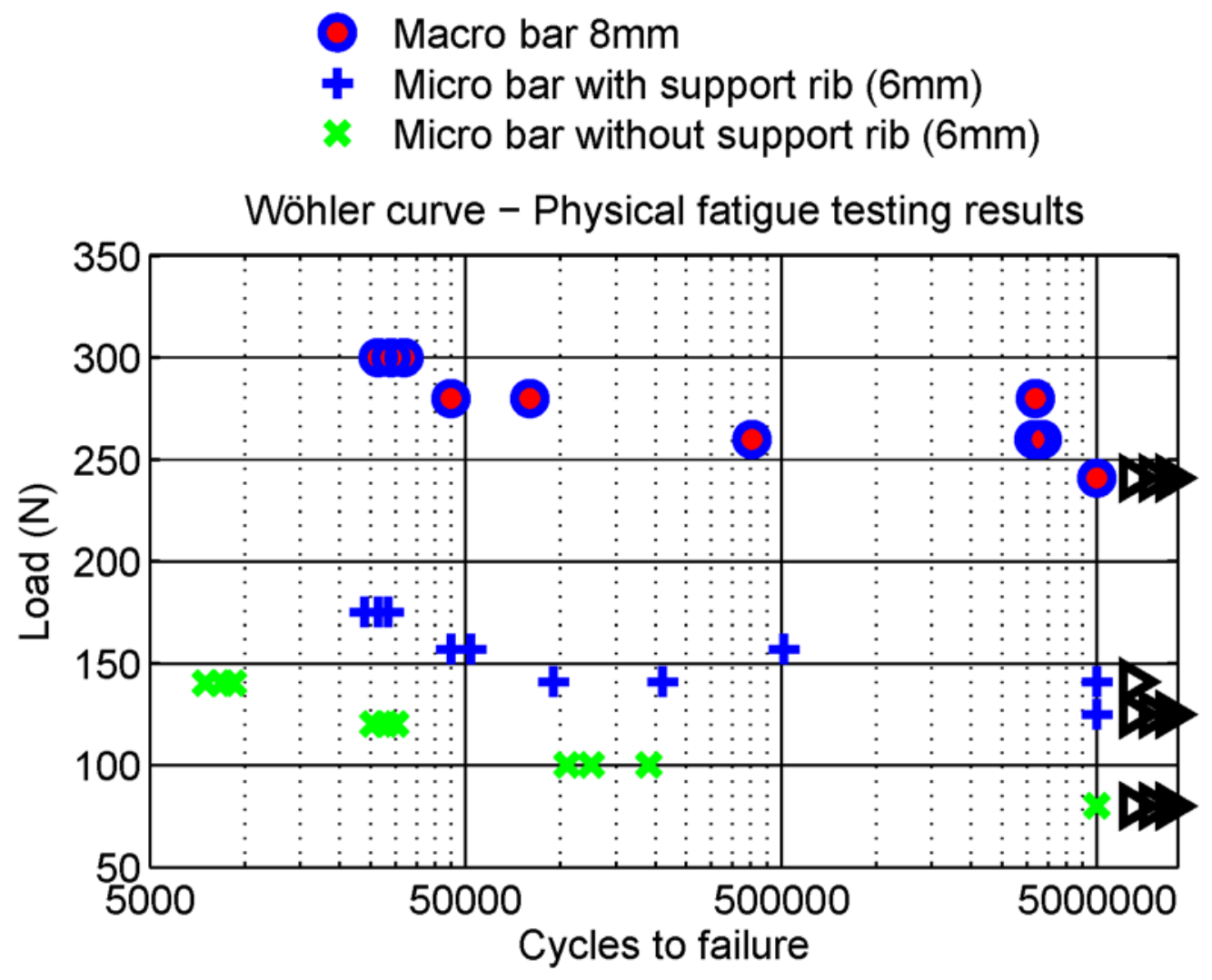




\section{Figure 5.}

FEA images (with stress distribution in MPa and resulting deformation) of a $150 \mathrm{~N}$ load application on an (top to bottom) Ackermann round $\varnothing 1.8 \mathrm{~mm}$ bar without and with rib support at $6 \mathrm{~mm}$ away from the cylinder/extension junction, and on a Dolder Y-macro bar loaded at $8 \mathrm{~mm}$ respectively. The colour scale (blue corresponds to no stress, red indicates the location of maximal stress, identical scale for all three structures) indicates the values of the Von Mises stress (a combination of tensile and compressive stresses). These FEA images show a good correlation with the location of the fracture after fatigue strength test as shown on the left.
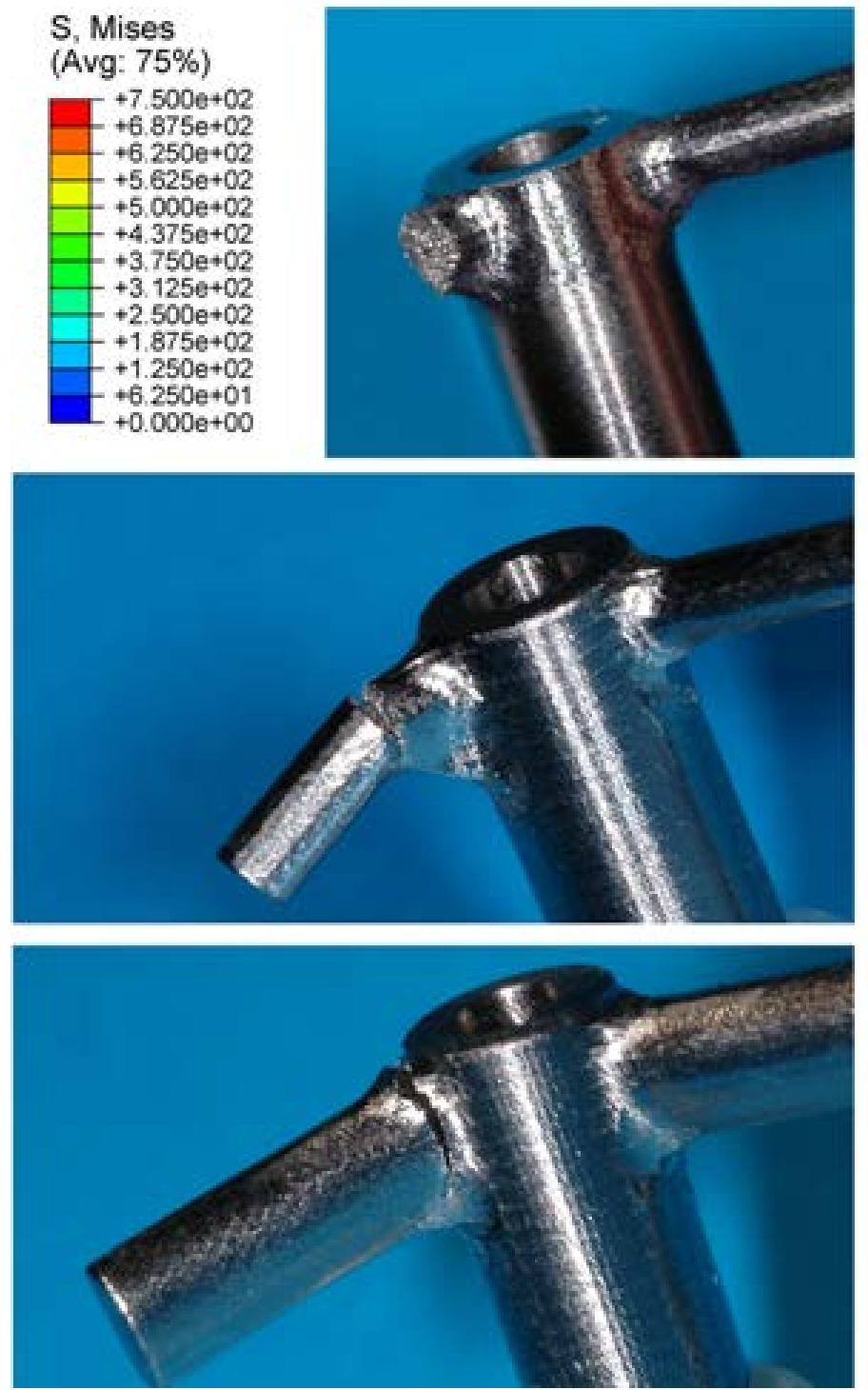
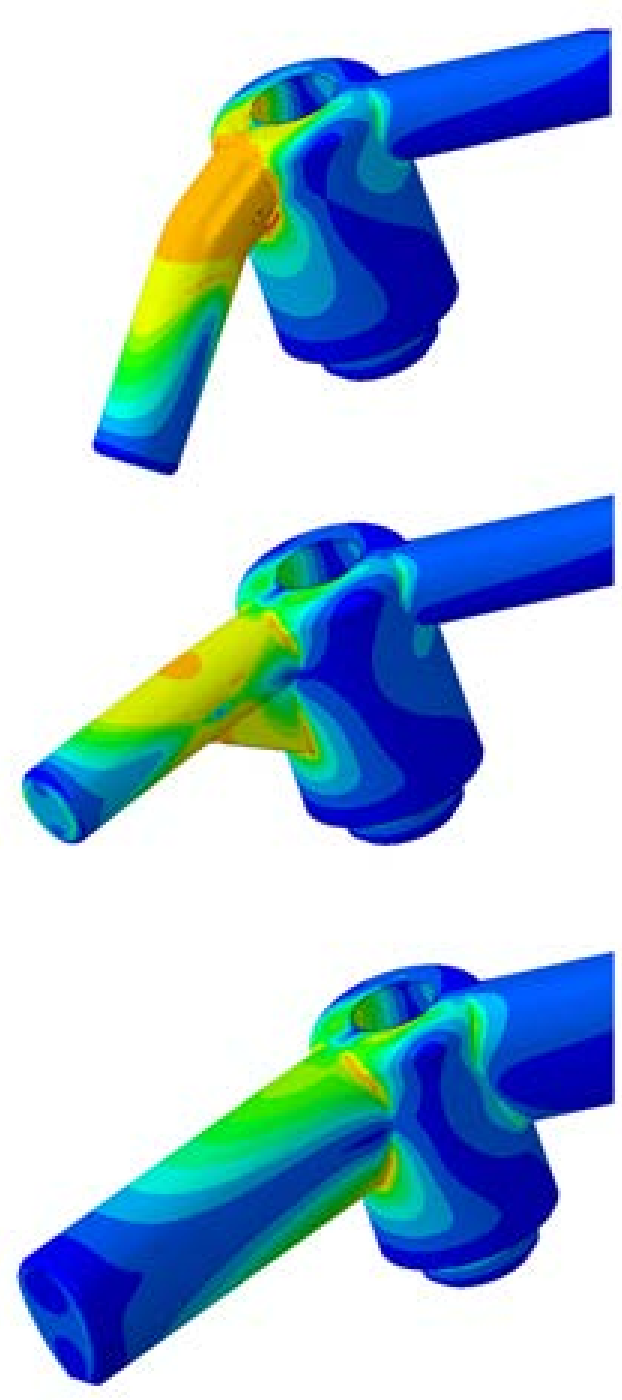